\title{
Preparation, Physicochemical Characterization and In-Vitro Dissolution Studies of Ketoprofen Solid Dispersion with PEG 6000 and HPMC 6 cps
}

\author{
Sharmin Akhter', A. K. M. Saif Uddin², Aninda Kumar Nath', Md. Salahuddin', \\ Mohammad Fahim Kadir ${ }^{4}$ and Md. Shahidul Islam ${ }^{5}$ \\ ${ }^{1}$ Department of Pharmacy, BGC Trust University Bangladesh, Chittagong-4381, Bangladesh \\ ${ }^{2}$ Department of Pharmacy, University of Asia Pacific, Dhaka, Bangladesh \\ ${ }^{3}$ Department of Livestock services, Dhaka, Bangladesh \\ ${ }^{4}$ SUNY Downstate Medical Center, Brooklyn, New York \\ ${ }^{5}$ Department of Pharmacy, University of Science and Technology Chittagong (USTC), Bangladesh
}

(Received: January 20, 2020; Accepted: January 28, 2020; Published: January 30, 2020)

\begin{abstract}
Ketoprofen [2-(3-benzoylphenyl)-propionic acid], a non-steroidal anti-inflammatory drug exhibits poor dissolution pattern. Solid dispersion (SD) techniques were used because it is particularly promising to improve the oral absorption and bioavailability of BCS Class II drugs. This investigation entails solid dispersion of ketoprofen which was formulated and characterized for better release profile and immediate action of the drug. Melting method was applied to prepare solid dispersion by using two immediate release (IR) polymer PEG 6000 and HPMC $6 \mathrm{cps}$ at different weight ratios. In the formulation, a fixed amount of lactose was used as adsorbent. The solid dispersions were investigated for drug entrapment efficiency and dissolution behavior. In vitro dissolution study was performed in phosphate buffer ( $\mathrm{pH}$ 7.4) medium for one hour. Percent cumulative drug release from solid dispersion was found to be minimum $92.19 \%$ and maximum $98.95 \%$ within one hour, which showed a better dissolution compared to the active drugs. Evaluation of the properties of the solid dispersion was also performed by using Scanning Electron Microscopy (SEM) study and Differential Thermal Analysis (DTA). SEM results indicated that ketoprofen crystallinity in SDs was significantly reduced, and that the majority of ketoprofen was in amorphous form. No interaction was found between drug and polymers from DTA and Fourier-transform infrared (FTIR) spectroscopy analysis. So, solid dispersion technique may be an effective technique to enhance dissolution rate of ketoprofen.
\end{abstract}

Key words: Solid dispersion, ketoprofen, melting method, SEM, DTA, FTIR.

\section{Introduction}

The term solid dispersion consisting of at least two different components, generally a hydrophillic matrix and a hydrophobic drug. The drug can be dispersed in molecular level either in amorphous clusters or in crystalline form (Dhirendra et al., 2009). Drugs those undergo dissolution, rate limited gastrointestinal absorption generally show improved dissolution and bioavailability as a result of reduction in particle size, so to say higher surface exposure. However, micronizing of drugs often leads to aggregation and agglomeration of particles, which results in poor wettability (Singh et al., 2011). Drug absorption from the GI tract can be limited by a variety of factors in which the most significant contributor having poor aqueous solubility and/or poor membrane permeability of the drug molecule. This article focuses on the former, in particular, the use of solid dispersion technique to improving the dissolution characteristics of poorly water-soluble drugs (Arunachalam et al., 2010). 
Ketoprofen, a Biopharmaceutical Classification System (BCS) class II drug, is a widely used NSAID having analgesic and antipyretic effect. It is freely soluble in ethanol, chloroform, acetone, ether, sparingly soluble in benzene and strong alkali, but practically insoluble in water. However, it has poor water solubility $\left(0.13 \mathrm{mg} / \mathrm{ml}\right.$ at $\left.25^{\circ} \mathrm{C}\right)$ which may predispose to formulation problems and limit its therapeutic applications and bioavailability (Pankajkumar et al., 2013). Based on these issues, an attempt was made to prepare solid dispersion formulation by using melting method with the help of PEG 6000 and HPMC $6 \mathrm{cps}$ in different weight ratios. By preparing this formulation, it is possible to release the drug immediately within very short time and this is beneficial in the view point of pharmaceutical industry.

\section{Materials And Methods}

\section{Materials}

Active ketoprofen was received as gift sample from Incepta Pharmaceuticals Ltd, Bangladesh. Here all analytical grade reagents like PEG 6000, HPMC 6 cps, lactose, potassium dihydrogen phosphate and sodium hydroxide were used for the study.

\section{Methods}

Preparation of solid dispersion of ketoprofen by melting method: Desired amount of ketoprofen and polymer (PEG 6000 and HPMC $6 \mathrm{cps}$ ) were taken in glass beaker and melted in hot water bath at $70^{\circ} \mathrm{C}$ to obtain a viscous mass. The viscous mass was stirred robustly by glass rod for getting uniformity of the mixture. Then it was kept at room temperature for five days until a solid mass was formed. The solidified mixture was ground by using a mortar and pestle and passed through the sieve (mesh size 40) to get solid dispersions. Finally, the resulting samples (SDs) were weighed and transferred in fresh glass vials with proper labeling and stored in a desiccator until further use (Islam et al., 2019).

In vitro dissolution study of solid dispersion: In vitro dissolution studies were performed as per established protocol (rpm 75, in phosphate buffer at $\mathrm{pH}$ 7.4. The release of drug was determined by UVspectrophotometric analysis at $258 \mathrm{~nm}$ (Mogal S. A et al., 2012).

Table 1. List of solid dispersion formulation of ketoprofen prepared by melting method.

\begin{tabular}{|c|c|c|c|c|}
\hline $\begin{array}{l}\text { Serial } \\
\text { No. }\end{array}$ & Formulation code & Carriers & $\begin{array}{l}\text { Drug polymer } \\
\text { ratio }\end{array}$ & Amounts \\
\hline 01 & E1 & PEG 6000 & $1: 1$ & $100 \mathrm{mg}: 100 \mathrm{mg}$ \\
\hline 02 & E2 & PEG 6000 & $1: 3$ & $100 \mathrm{mg}: 300 \mathrm{mg}$ \\
\hline 03 & E3 & PEG 6000 & $1: 5$ & $100 \mathrm{mg}: 500 \mathrm{mg}$ \\
\hline 04 & $\mathrm{~K} 1$ & $\begin{array}{l}\text { PEG 6000: HPMC } 6 \\
\text { cps: Lactose }\end{array}$ & 1: $0.5: 1.5: 5$ & $\begin{array}{l}200 \mathrm{mg}: 100 \mathrm{mg}: \\
300 \mathrm{mg}: 1 \mathrm{gm}\end{array}$ \\
\hline 05 & $\mathrm{~K} 2$ & $\begin{array}{l}\text { PEG 6000: HPMC } 6 \\
\text { cps: Lactose }\end{array}$ & $1: 0.5: 1: 5$ & $\begin{array}{l}200 \mathrm{mg}: 100 \mathrm{mg}: \\
200 \mathrm{mg}: 1 \mathrm{gm}\end{array}$ \\
\hline 06 & K3 & $\begin{array}{l}\text { PEG 6000: HPMC } 6 \\
\text { cps: Lactose }\end{array}$ & $1: 0.5: 0.5: 5$ & $\begin{array}{l}200 \mathrm{mg}: 100 \mathrm{mg}: \\
\text { 100mg: } 1 \mathrm{gm}\end{array}$ \\
\hline 07 & $\mathrm{~K} 4$ & $\begin{array}{l}\text { PEG 6000: HPMC } 6 \\
\text { cps: Lactose }\end{array}$ & 1: $0.5: 0.00: 5$ & $\begin{array}{l}200 \mathrm{mg}: 100 \mathrm{mg}: \\
000 \mathrm{mg}: 1 \mathrm{gm}\end{array}$ \\
\hline
\end{tabular}

Preparation of phosphate buffer ( $p H$ 7.4): 6.8 gm of potassium di-hydrogen phosphate $\left(\mathrm{KH}_{2} \mathrm{PO}_{4}\right)$ dissolved in $1000 \mathrm{ml}$ distilled water. To maintain the pH 7.4 sodium hydroxide solution was used.
Preparation of standard curve for ketoprofen: 10 $\mathrm{mg}$ of ketoprofen was taken in a $100 \mathrm{ml}$ volumetric flask and makes up the volume with phosphate buffer (pH 7.4) and named it stock solution, its concentration was $0.1 \mathrm{mg} / \mathrm{ml}$. From the above 
solution $0.1,0.2,0.4,0.6,0.8$ and $1 \mathrm{ml}$ was taken in $10 \mathrm{ml}$ volumetric flask and makes up the volume. Its concentration was $1,2,4,6,8,10 \mu \mathrm{g} / \mathrm{ml}$. The average values of absorbance values were plotted against respective drug concentration and thus standard curve of ketoprofen was produced (Figures 1) (Akhter et al., 2016).

Drug entrapment efficiency (DEE) studies: 50 $\mathrm{mg}$ of formulation was taken in $100 \mathrm{ml}$ phosphate buffer solution. After filtration, $10 \mathrm{ml}$ filtrate solution was taken in a volumetric flask and the volume was adjusted to $100 \mathrm{ml}$ by phosphate buffer and the absorbance was taken at $258 \mathrm{~nm}$. From the absorbance value the amount of drug entrapped was determined using standard curve (Farheen et al., 2017). The drug entrapment efficiency was calculated by using the following equation -

$$
\text { Entrapment efficiency }(\%)=\frac{\text { Calculated drug concentration }}{\text { Theoretical drug concentration }} \times 100 \%
$$

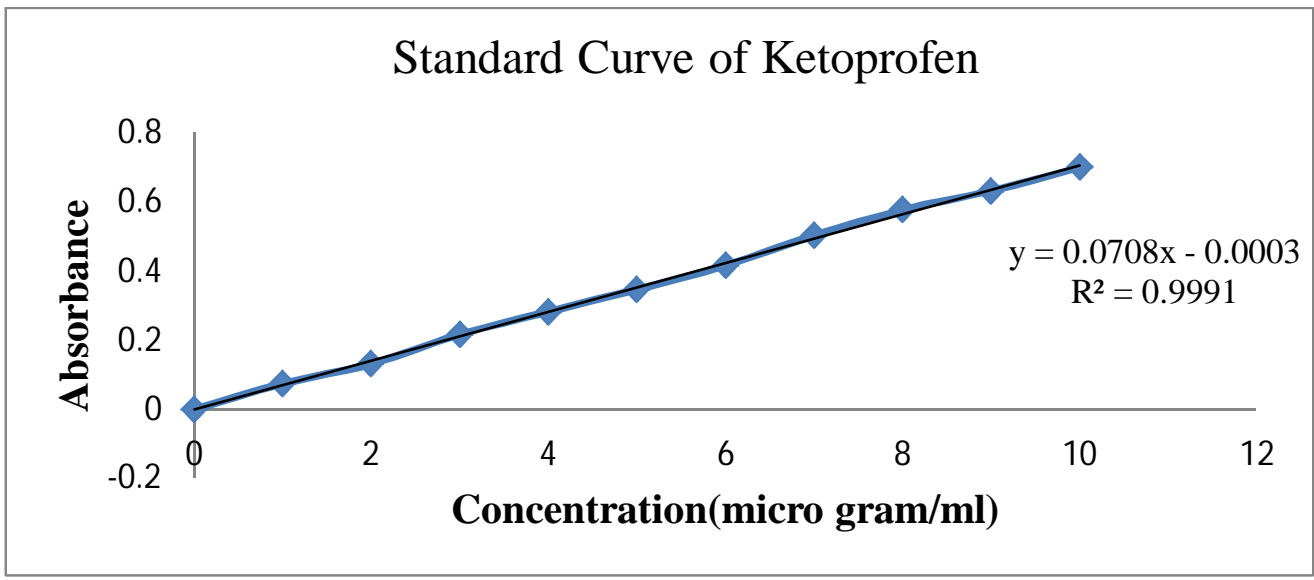

Figure 1. Standard curve of ketoprofen.

Kinetic data analysis: The drug release kinetic studies carried out for solid dispersion formulations were evaluated using the linear regression method:

(1) Zero order kinetic model - cumulative \% of drug released versus time $(T)$;

(2) First order kinetic model - log cumulative percent drug remaining versus time $(T)$;

(3) Higuchi's model - cumulative percent drug released versus square root of time (T);

(4) Korsmeyer-Peppas model - log cumulative percent drug released versus log time $(T)$ and

(5) Hixson-Crowell model - Cube root of initial amount - Cube root of drug remaining versus time (T) (Ryakala et al., 2015).

\section{Characterization of SDs}

Fourier transform infrared spectrophotometric (FTIR) analysis: The FTIR spectrum of the active drug and solid dispersion formulation were obtained in the range of $4000-6000 \mathrm{~cm}^{-1}$ using FTIR spectrophotometer (Zakaria et al., 2014).

Differential thermal analysis (DTA): Thermal analysis was performed using DTA instrument under nitrogen flow of $20 \mathrm{ml} / \mathrm{min}$. Approximately $1.0 \mathrm{mg}$ of ketoprofen, and solid dispersion were placed in a sealed aluminum pan and heated at a rate of $10^{\circ} \mathrm{C} / \mathrm{min}$ from $30^{\circ} \mathrm{C}$ to $220^{\circ} \mathrm{C}$ (Sinha et al., 2010).

Surface morphology study by scanning electron microscope (SEM): Scanning electron microscopy was used to study the morphology and surface topology of the solid power particles (Akhter et al., 2016). 


\section{Result And Discussion}

Physical appearance: All solid dispersions were white fine powders. No discolouration was observed during preparation of SD.

Drug entrapment efficiency (DEE): From table 2 it is found that Drug Entrapment Efficiency (DEE) was suitable and ranged from $87.82 \%$ to $98.52 \%$. DEE\% was increased with increased polymeric concentrations. E3 and K1 exhibited the highest \% of DEE of $98.52 \%$ and $96.96 \%$, respectively and E1 showed minimum DEE\% of $87.82 \%$. Considering the amount of polymers used in E1, E3 and K1 the current investigation suggests that drug entrapment efficiency (DEE) increases with increasing polymeric concentrations.

Table 2. Drug entrapment efficiency of ketoprofen solid dispersion formulations.

\begin{tabular}{lc}
\hline Formulation code & $\begin{array}{l}\text { Drug entrapment } \\
\text { efficiency (\%) }\end{array}$ \\
\hline E1 & 87.82 \\
E2 & 95.8 \\
E3 & 98.52 \\
K1 & 96.90 \\
K2 & 93.76 \\
\hline
\end{tabular}

In vitro dissolution studies of active Ketoprofen and solid dispersion formulations: The in vitro dissolution characteristics of different types of preparations were compared with active drug. The solid dispersions of ketoprofen prepared by melting method with PEG 6000 and HPMC $6 \mathrm{cps}$ showed improved dissolution when compared with active drug. It is due to the use of hydrophilic polymer. PEGs have the ability to solubilize some compounds and improve wettability. The solid dispersion of drugs with PEG 6000 may be useful to increase stability, solubility, dissolution and bioavailability of poorly water-soluble drug. Lactose was utilized as an adsorbent for the preparation of solid dispersion. The role of HPMC 6 cps was as crystallization inhibitor and to prevent recrystallization of poorly watersoluble drug. The effect of PEG 6000 and HPMC 6 cps on percent release of ketoprofen are represented in table 3.

Ketoprofen was released only $31.88 \%$ after 5 min and $45.61 \%$ within 60 min from active drug. On the other hand, solid dispersion formulation batches E1-E3 and K1-K4 have shown an immediate release profile between $92.19 \%$ and $98.95 \%$ within $60 \mathrm{~min}$ where E3 and K1 showed highest percent of drug release $(98.95 \%$ and $98.50 \%$ respectively) after 60 $\min$.

Table 3. In vitro drug release data of ketoprofen and different ketoprofen solid formulation.

\begin{tabular}{|c|c|c|c|c|c|}
\hline $\begin{array}{l}\text { Formulation } \\
\text { no }\end{array}$ & $\begin{array}{l}\text { Formulation } \\
\text { code }\end{array}$ & $\begin{array}{l}\text { Drug polymer } \\
\text { And ratios }\end{array}$ & $\begin{array}{l}\text { Percent release of } \\
\text { drug (after } 5 \mathrm{~min} \text { ) }\end{array}$ & $\begin{array}{l}\text { Percent release of } \\
\text { drug (after } 30 \mathrm{~min} \text { ) }\end{array}$ & $\begin{array}{l}\text { Percent release of } \\
\text { drug (after } 60 \mathrm{~min} \text { ) }\end{array}$ \\
\hline 1. & $\begin{array}{c}\text { Active } \\
\text { ketoprofen }\end{array}$ & $-\cdots--$ & $31.88 \%$ & $40.84 \%$ & $45.617 \%$ \\
\hline 2. & E1 & Ketoprofen: PEG $6000(1: 1)$ & $43.84 \%$ & $71.70 \%$ & $97.93 \%$ \\
\hline 3. & E2 & Ketoprofen: PEG $6000(1: 3)$ & $56.06 \%$ & $77.87 \%$ & $98.71 \%$ \\
\hline 4. & $\mathbf{E 3}$ & Ketoprofen: PEG 6000 (1:5) & $53.20 \%$ & $85.99 \%$ & $98.95 \%$ \\
\hline 5. & K1 & $\begin{array}{l}\text { Ketoprofen: PEG 6000: } \\
\text { HPMC } 6 \text { CPS: Lactose }(1: \\
0.5: 1.5: 5)\end{array}$ & $48.34 \%$ & $81.21 \%$ & $96.48 \%$ \\
\hline 6. & K2 & $\begin{array}{l}\text { Ketoprofen: PEG 6000: } \\
\text { HPMC } 6 \text { CPS: Lactose } \\
(1: 0.5: 1: 5)\end{array}$ & $51.14 \%$ & $75.37 \%$ & $96.48 \%$ \\
\hline 7. & K3 & $\begin{array}{l}\text { Ketoprofen: PEG 6000: } \\
\text { HPMC } 6 \text { CPS: Lactose } \\
(1: 0.5: 0.5: 5)\end{array}$ & $48.41 \%$ & $82.90 \%$ & 94.47 \\
\hline 8. & K4 & $\begin{array}{l}\text { Ketoprofen: PEG 6000: } \\
\text { HPMC 6 CPS: Lactose } \\
(1: 0.5: 0.00: 5)\end{array}$ & $42.02 \%$ & $76.60 \%$ & $91.19 \%$ \\
\hline
\end{tabular}


Release kinetics analysis: Different release kinetics plot (zero order plot, first order plot, Higuchi plot, Korsmeyer-peppas plot, HixsonCrowell plot) are shown in figure 2 to 13 . The release rate constant and correlation co-efficient $\left(\mathrm{R}^{2}\right)$ value

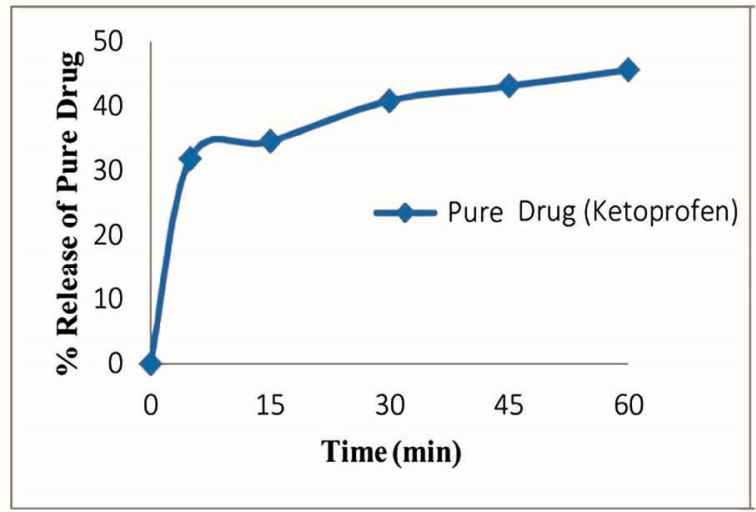

Figure 2. Zero order plot of ketoprofen.

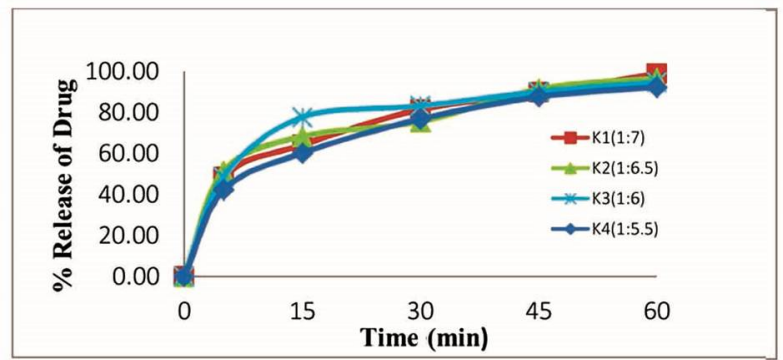

Figure 4. Zero order plot of ketoprofen solid dispersion formulations containing PEG 6000 and HPMC 6 cps (K1-K4).

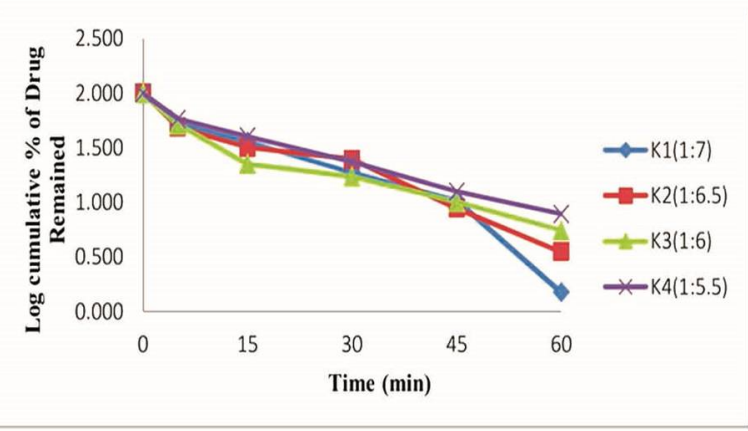

Figure 6. First order plot of ketoprofen solid dispersion formulations containing PEG 6000 and HPMC $6 \mathrm{cps}$ (K1-K4). and the best fit model and mechanism of drug release from ketoprofen solid dispersion batches E1, E2, E3, $\mathrm{K} 1, \mathrm{~K} 2, \mathrm{~K} 3$ and $\mathrm{K} 4$ are represented in table 4 and table 5 respectively.

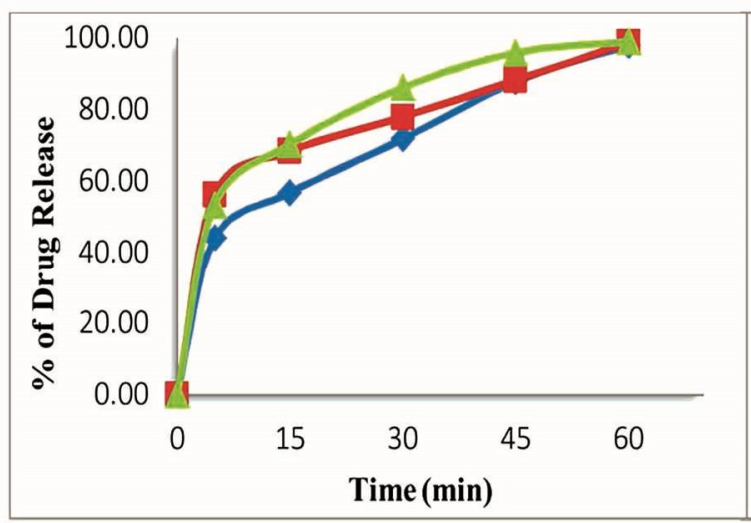

Figure 3. Zero order plot of ketoprofen solid dispersion formulations containing PEG 6000 (E1-E3).

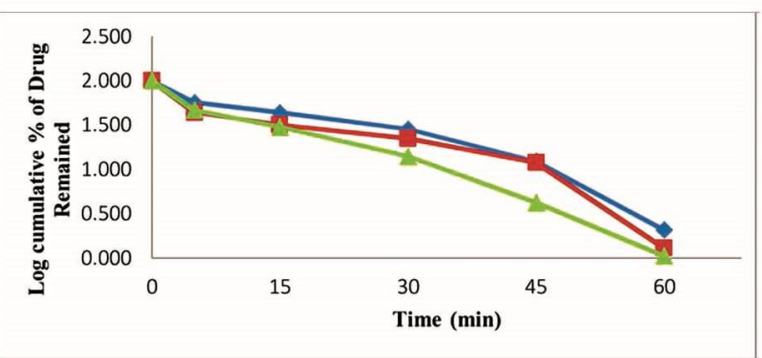

Figure 5. First order plot of ketoprofen solid dispersion formulations containing PEG 6000 (E1-E3).

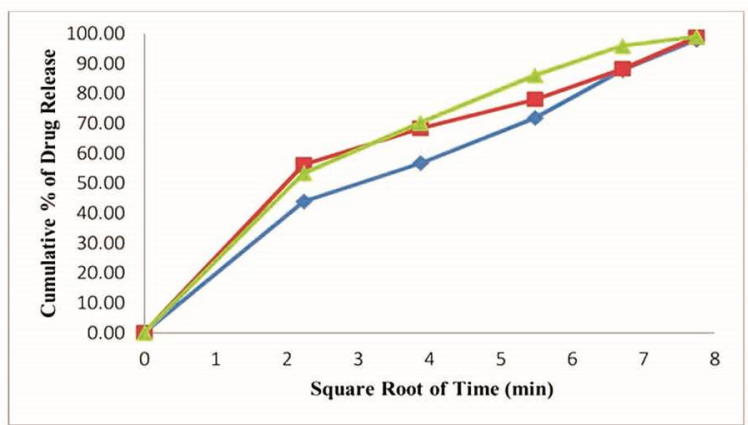

Figure 7. Higuchi plot of ketoprofen solid dispersion formulations containing PEG 6000 (E1-E3). 


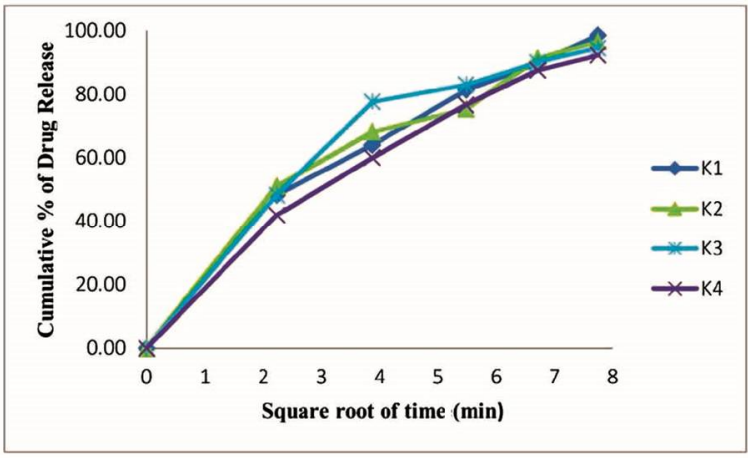

Figure 8. Higuchi plot of ketoprofen solid dispersion formulations containing PEG 6000 and HPMC $6 \mathrm{cps}$ (K1-K4).

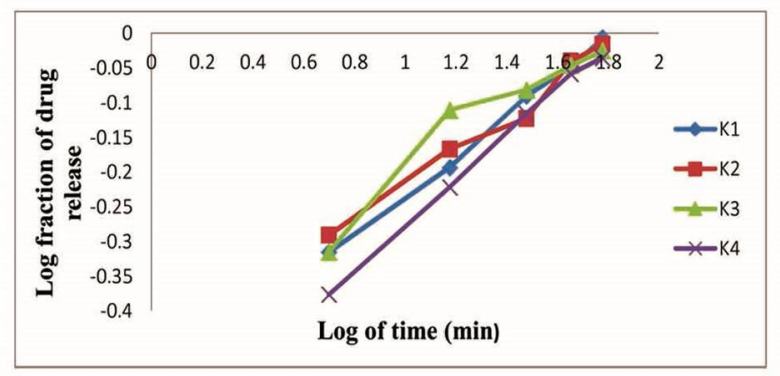

Figure 10. Korsmeyer-Peppas plot of ketoprofen solid dispersion formulations containing PEG 6000 and HPMC 6 cps (K1-K4).

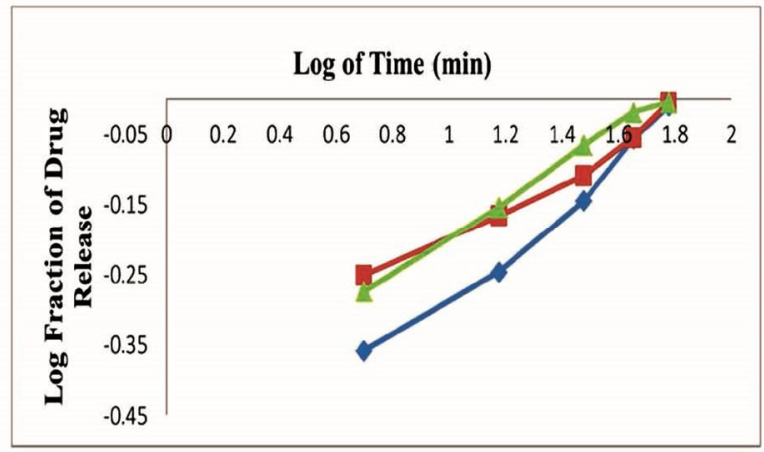

Figure 9. Korsmeyer-Peppas plot of ketoprofen solid dispersion formulations containing PEG 6000 (E1E3).

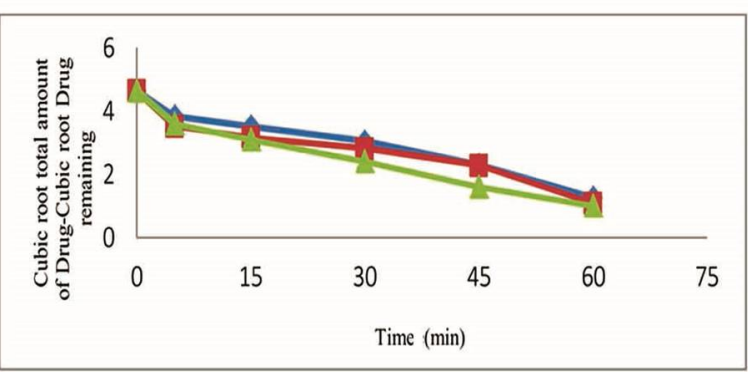

Figure 11. Hixson-Crowell plot of ketoprofen solid dispersion formulations containing PEG 6000 (E1E3).

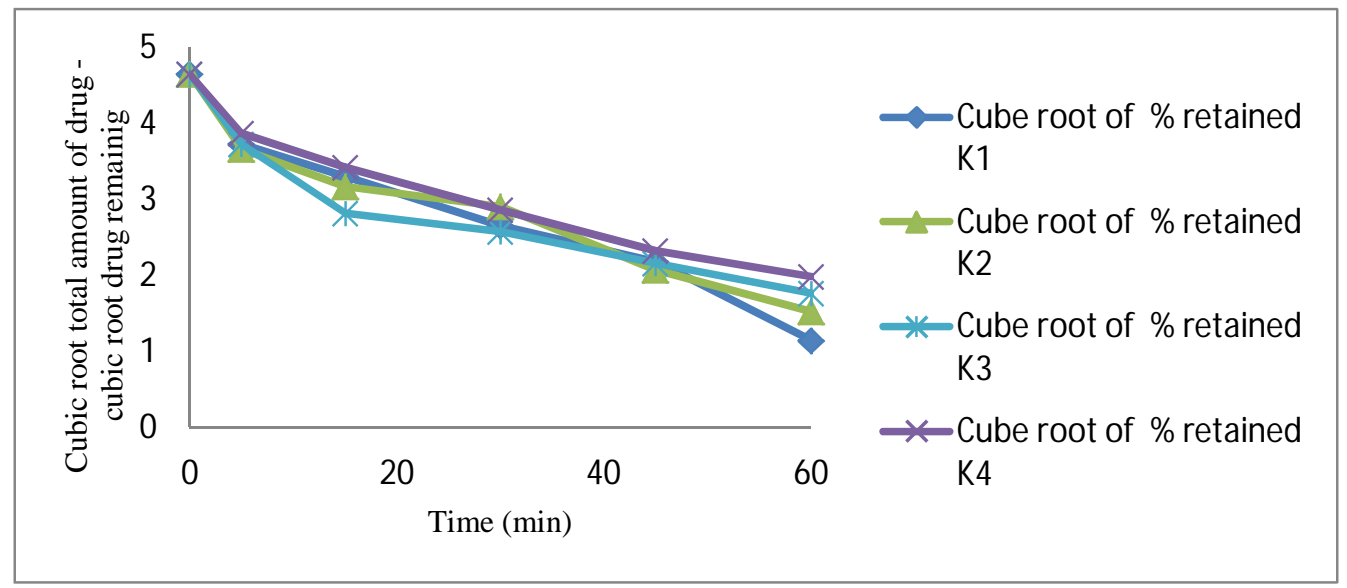

Figure 12. Hixson-Crowell plot of ketoprofen solid dispersion formulations containing PEG 6000 and HPMC 6 cps (K1-K4). 
Table 4. Y-equation $(Y=a X+b)$ and correlation co-efficient $\left(R^{2}\right)$ of SDs formulation of ketoprofen.

\begin{tabular}{llllllllll}
\hline $\begin{array}{l}\text { Formulation } \\
\text { code }\end{array}$ & \multicolumn{2}{c}{ Zero order } & \multicolumn{3}{c}{ First order } & \multicolumn{2}{c}{ Higuchi model } & $\begin{array}{c}\text { Hixon-crowell } \\
\text { model }\end{array}$ & $\begin{array}{l}\text { Korsmeyer- } \\
\text { peppas }\end{array}$ \\
\cline { 2 - 10 } & $\mathrm{K}_{0}$ & $\mathrm{R}^{2}$ & $\mathrm{~K}_{1}$ & $\mathrm{R}^{2}$ & $\mathrm{~K}_{\mathrm{h}}$ & $\mathrm{R}^{2}$ & $\mathrm{~K}_{\mathrm{hx}}$ & $\mathrm{R}^{2}$ & $\mathrm{n}$ Value \\
\hline $\mathrm{E} 1$ & 1.370 & 0.837 & -0.024 & 0.926 & 1.21 & 0.67 & 1.07 & 0.56 & 0.324 \\
$\mathrm{E} 2$ & 1.255 & 0.709 & -0.026 & 0.889 & 1.17 & 0.55 & 1.77 & 0.70 & 0.219 \\
$\mathrm{E} 3$ & 1.337 & 0.718 & -0.030 & 0.983 & 1.35 & 0.29 & 1.38 & 0.39 & 0.258 \\
$\mathrm{~K} 1$ & 1.342 & 0.770 & -0.026 & 0.938 & 1.28 & 0.55 & 1.77 & 0.49 & 0.288 \\
$\mathrm{~K} 2$ & 1.282 & 0.735 & -0.021 & 0.964 & 1.19 & 0.55 & 1.88 & 0.61 & 0.252 \\
$\mathrm{~K} 3$ & 1.244 & 0.663 & -0.018 & 0.932 & 1.49 & 0.22 & 1.35 & 0.72 & 0.259 \\
$\mathrm{~K} 4$ & 1.306 & 0.789 & -0.017 & 0.982 & 1.27 & 0.65 & 1.80 & 0.89 & 0.324 \\
\hline
\end{tabular}

Table 5. The best fit model and mechanism of drug release.

\begin{tabular}{cccc}
\hline Formulation No & Best fit model & n Value & Release mechanism \\
\hline E1 & First Order & 0.324 & Fickian transport \\
E2 & First Order & 0.219 & Fickian transport \\
E3 & First Order & 0.258 & Fickian transport \\
K1 & First Order & 0.288 & Fickian transport \\
K2 & First Order & 0.252 & Fickian transport \\
K3 & First Order & 0.259 & Fickian transport \\
K4 & First Order & 0.324 & Fickian transport \\
\hline
\end{tabular}

Fourier transform infrared spectroscopic (FTIR) analysis: Fourier transform infrared spectroscopic studies were conducted for the active drug (Ketoprofen) and the solid dispersion formulation batch K1 (Ketoprofen, PEG6000, HPMC 6 cps and lactose). The FTIR spectra are shown in Figure 14 and 15 .

Figure 14 and 15 represent the FTIR spectra of active ketoprofen and batch K1 (Ketoprofen, PEG6000, HPMC 6cps and lactose). Now if this spectrum is compared with the spectra of ketoprofen then we found that aromatic C-H stretch, carboxylic acid O-H stretch are present at 2978.09. C-H stretch plus $\mathrm{OH}$ deformation, $(\mathrm{C}=\mathrm{O}$ stretch $)$ and $\mathrm{CH}-\mathrm{CH} 3$ deformation, are present at 2883.58, 1653.00 and 1440.83 respectively. Another carboxylic O-H out of plane deformation and $\mathrm{C}-\mathrm{H}$ out of plane deformation for substituted aromatic were seen at 1695.43 and 842.89 , respectively.

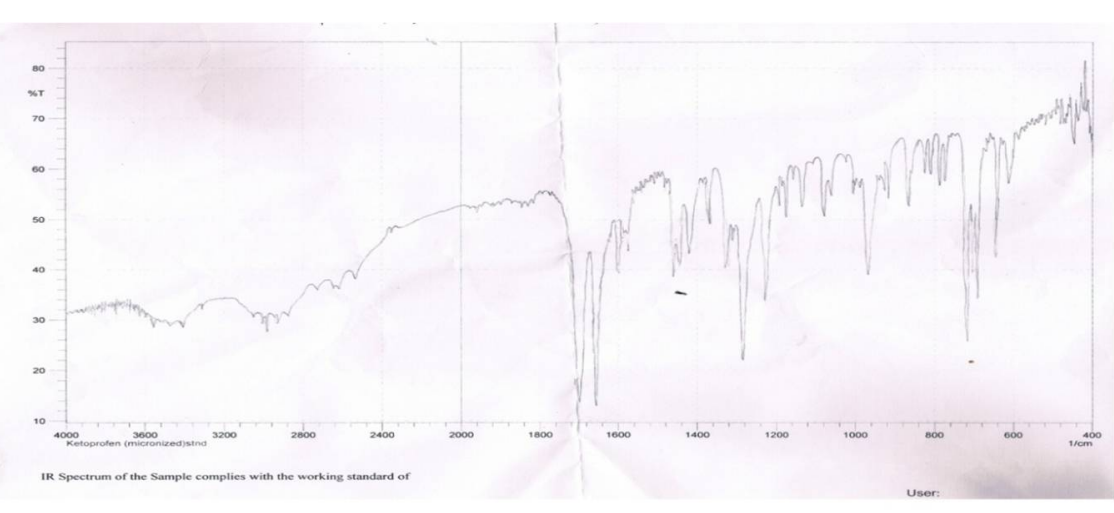

Figure 14. FTIR spectrum of active ketoprofen. 


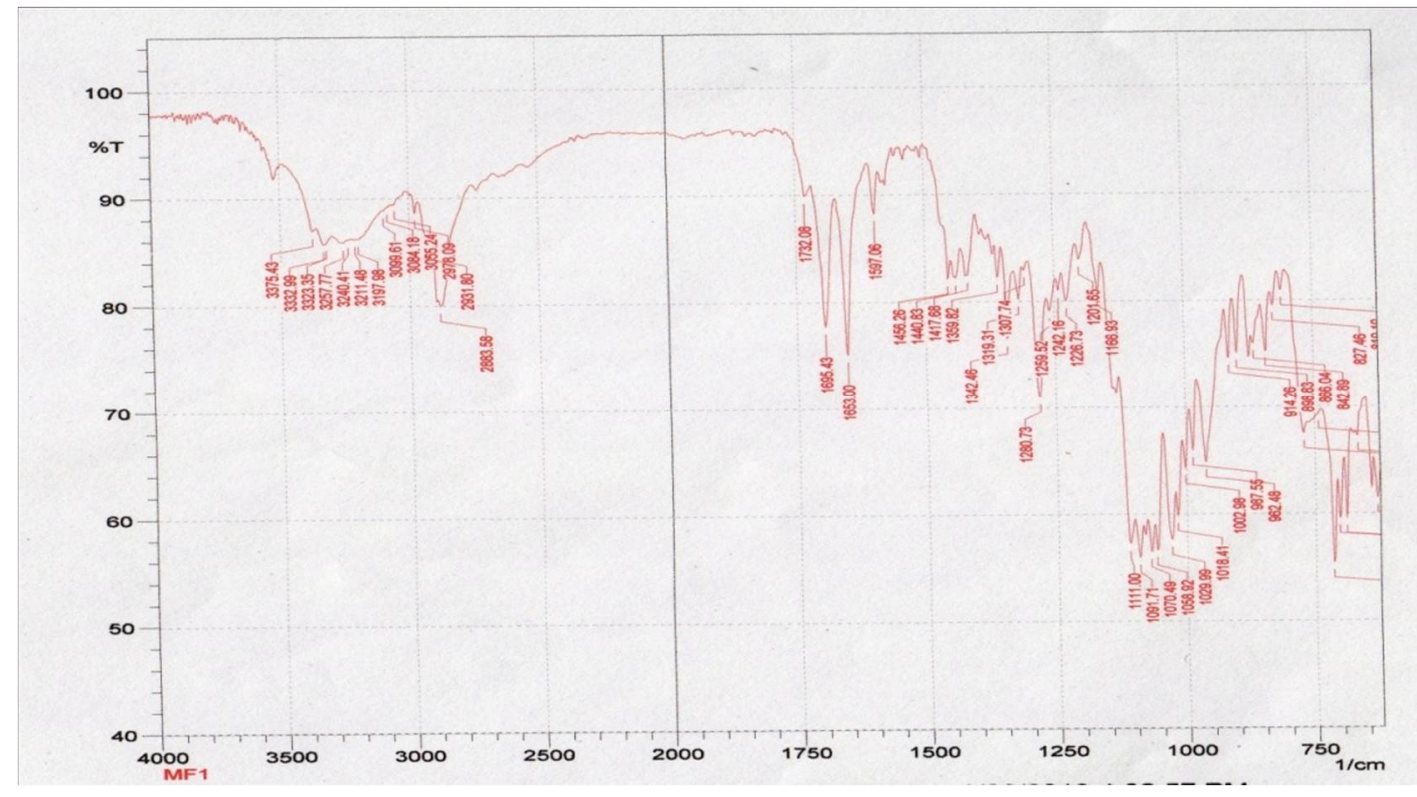

Figure 15. FTIR Spectrum of K1 (Ketoprofen, PEG 6000, HPMC 6 cps and lactose).

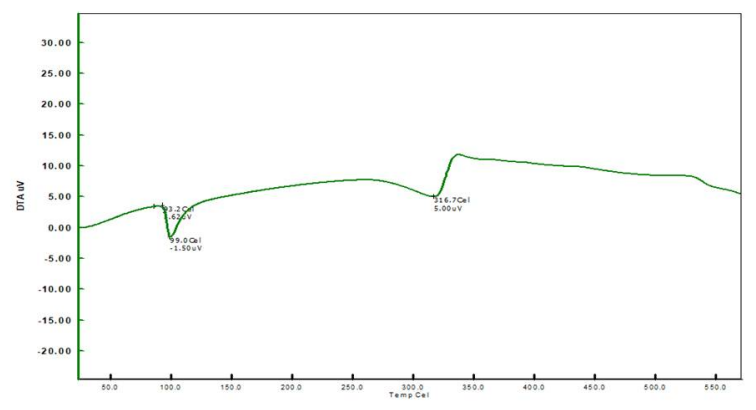

Figure 16. DTA of pure drug (ketoprofen).

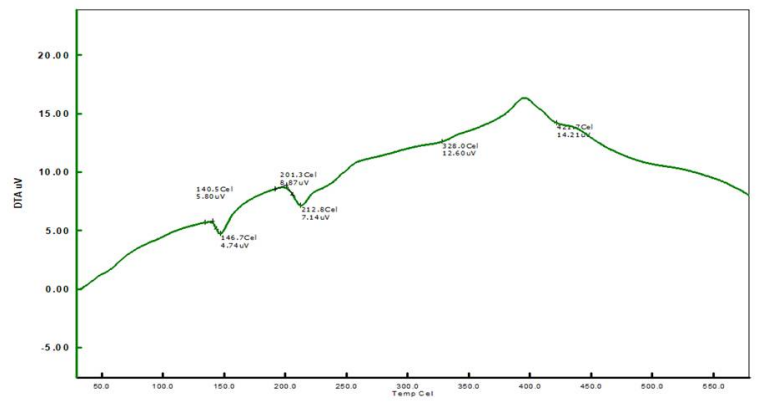

Figure 17. DTA of batch K1 (ketoprofen, PEG6000, HPMC 6cps and lactose).

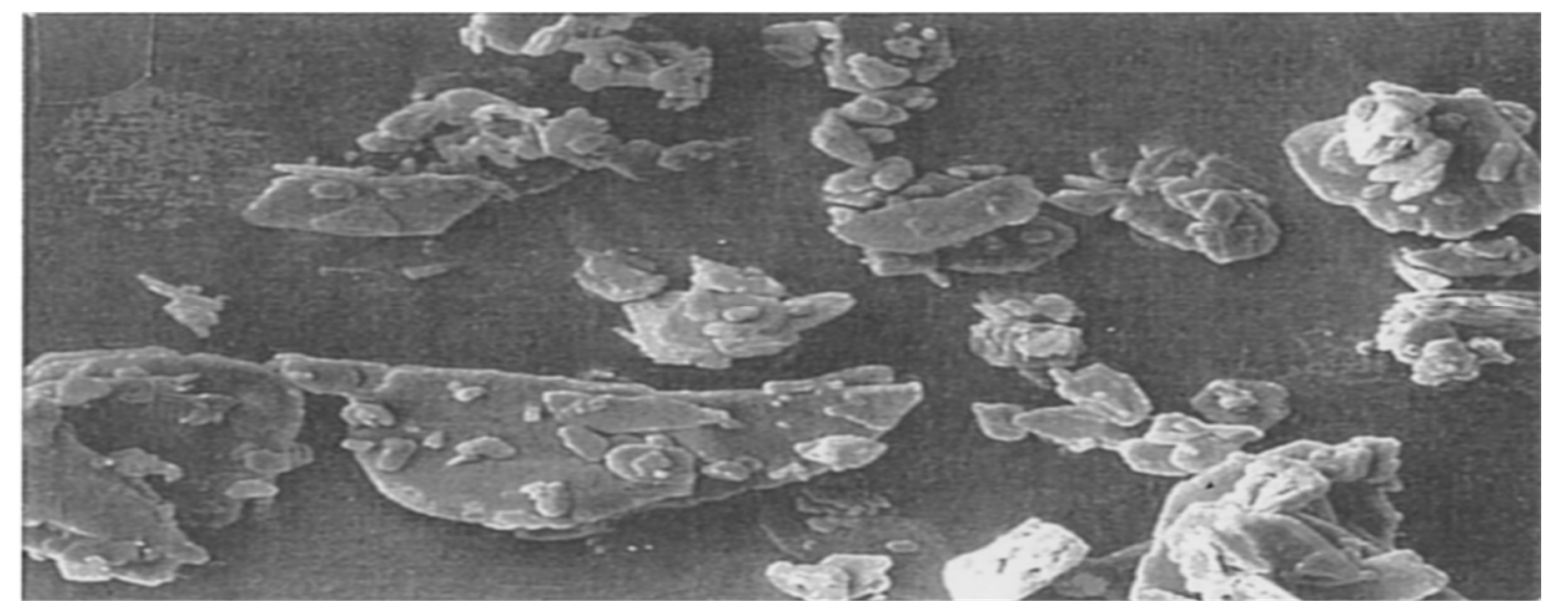

Figure 18. Scanning electronic microscopic image of ketoprofen. 


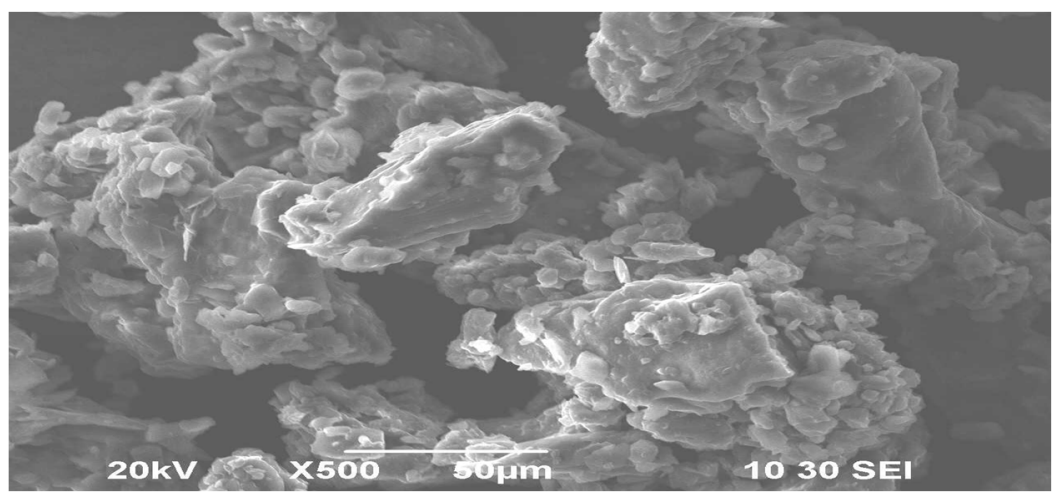

Figure 19. Scanning electronic microscopic image of solid dispersion containing ketoprofen with PEG 6000, HPMC 6 cps and lactose.

Differential thermal analysis (DTA): The DTA thermograms of the ketoprofen and SDs batch K1 are shown in figure 16 and 17, respectively. Figure 16 exhibited a single endothermic response corresponding to the melting of drug. Onset of melting was observed at $99^{\circ} \mathrm{C}$. Thermograms of solid dispersion (Figure 17) showed the absence of a ketoprofen peak, suggesting that ketoprofen is completely soluble in the liquid phase of polymer or absence of crystalline nature of ketoprofen. However, the melting peak of batch $\mathrm{K} 1$ in SDs was observed at $146.7^{\circ} \mathrm{C}$.

Scanning electron microscopic (SEM) analysis: Active ketoprofen and solid dispersion of ketoprofen (K1) containing PEG 6000 and HPMC 6 cps were examine by SEM to see the morphological change that occurred due to formulation variation. SEM studies showed that the surface morphological properties of the solid dispersion was in amorphous state. The surface morphology and representative micrographs are shown in Figures 18 and 19.

\section{Conclusion}

Ketoprofen solid dispersions were prepared by melting method. The method was easy, economical and modest. It showed faster dissolution characteristics as compared to active ketoprofen. The solid dispersion of ketoprofen in PEG 6000 (1:5) allowed to achieve of $85 \%$ dissolved drug after only 30 minutes. The most effective system was ketoprofen: PEG 6000: HPMC 6 cps: lactose which allowed to achieve $98 \%$ to dissolved drug after 60 minutes. It can be concluded that with carefully designed experimental technique, solubility of poorly water-soluble drugs can be improved by using solid dispersion technique.

\section{Acknowledgements}

The authors are grateful to University of Asia Pacific, Dhaka for providing laboratory support during the study. We are also thankful to Bangladesh Council of Scientific and Industrial Research (BCSIR), Dhaka, Bangladesh for SEM and FTIR analysis and Incepta Pharmaceuticals Limited, Bangladesh for giving the drug sample as gift.

\section{Conflict of interest}

The authors declare no conflict of interest.

\section{References}

Akhter, S., Hossen, S. M., Salahuddin, M., Sunny, A. M., Sathi, A. F. and Islam, S. M. 2019. In vitro dissolution study of glimepiride from binary and ternary solid dispersion formulation. Universal J. Pharm. Res. 4, 7 12.

Akhter, S., Uddin, M. K. A., Salahuddin, M., Marium, M., Alam, B. M., Barua, S., Chakrabarty, P. and Kadir, F. M. 2016. Formulation and evaluation of solid dispersion of an anti-epileptic drug carbamazepine. IOSR J. Pharma. Bio. Sci. 11, 61-68.

Akhter, S., Uddin, S. M. K. A., Salahuddin, M., Mia, W. M., Kumar, K. S., and Kadir, F. M. 2016. In-vitro evaluation of binary and ternary carbamazepine solid dispersion. Asian Australas. J. Biosci. Biotechnol. 1, 213-220. 
Arunachalam, A., Karthikeyan. M., Konam. K., Prasad, P. H., Sethuraman, S., and Ashutoshkumar, A. 2010. A review on solid dispersion. J. Curr. Pharm. Res. 1, 82-90.

Dhirendra, K., Lewis, S. and Udupan, A. K. 2009. Solid dispersions: a review. Pak. J. Pharm. Sci. 22, 234-246.

Farheen, T., Shaikh, A. and Shahi, S. 2017. Fabrication and characterization of mucoadhesive microsphere of oral hypoglycemic drug. World J. Pharm. Pharm. Sci. 6, 763-774.

Mogal, S. A., Gurjar, P. N., Yamgar, D. S. and Kamod, A. C. 2012. Solid dispersion technique for improving solubility of some poorly soluble drugs. Pharm. Lett. 4, 1574-1586.

Naidu, N. B., Chowdary, K. P., Murthy, K.V., Satyanarayana, V., Hayman, A. R. and Becket, G. 2004. Physicochemical characterization and dissolution properties of meloxicam-cyclodextrin binary systems. J. Pharm. Biomed. Anal. 35, 75-86.

Noyes, A. A. and Whitney, W. R. 1987. The rate of solution of solid substances in their own solution. $J$. Am. Chem. Soc. 19, 930-934.
Pankajkumar, S., Yadav, Kumar, V., Singh, P. U., Bhat, R. $\mathrm{H}$ and Mazumder, B. 2013. Physicochemical characterization and in vitro dissolution studies of solid dispersion of ketoprofen with PVP K30 and Dmannitol. Saudi Pharm. J. 21, 77-84.

Ryakala, H., Dineshmohan, S., Ramesh, A. and Gupta, M. R. V. 2015. Formulation and in vitro evaluation of bilayer tablets of nebivolol hydrochloride and nateglinide for treatment of diabetes and hypertension. J. Drug. Deliv. 2015, 1-14.

Singh, S., Baghel, R. S. and Yadav, L. 2011. A review on solid dispersion. Int. J. Pharm. Life Sci. 2, 1078-1095.

Sinha, S., Ali, M., Baboota, S., Ahuja, A., Kumar, A and Ali, J. 2010. Solid dispersion as an approach for bioavailability enhancement of poorly water-soluble drug ritonavir. AAPS Pharm. Sci. Tech. 11, 518- 527.

Zakaria F. M., Rishikesh, R. E., Akhter, R. and Bhuiyan, A. M. 2014. Design, formulation and solubility enhancement of fenofibrate, a water insoluble drug by solid dispersion technique. World J. Pharm. Res. 3, 1801-1814. 